\title{
The planning of benching and services for the modern pathological laboratory
}

\author{
K. M. LAURENCE \\ From the Department of Paediatric Pathology, Welsh National School of Medicine, \\ Llandough Hospital, Penarth, Glam.
}

SYNOPSIS The principles which should govern the planning of benching and services for neiu laboratories are enumerated. These include the necessity for long-term planning, flexibility, an\& economy.

The 'Cardiff benching system' where the benches are composed of units that consist of an in? dependent movable table base, a removable bench top, a 6 in. insertion, which enables the bench height to be changed from 30 in. to 36 in., and a variety of movable underbench cupboards, angु where all services are carried on service spines, is described. The extreme flexibility of this type of benching and servicing is illustrated.

Many of those working in older laboratories are familiar with cramped accommodation and inconveniently arranged working surfaces. Tasks intended to be carried out standing are often performed at a bench designed for sitting, while sitting tasks such as microscopy are frequently performed at a bench of standing height, with the worker having to get on and off a telephonist's chair. In many older and some modern laboratories insufficient knee spaces are provided to enable the staff to work in reasonable comfort. Such situations are undesirable as they lead to unnecessary irritation and fatigue and thus predispose to inaccuracies. It is, however, more serious when short technicians have to climb to read instruments placed on fixed high benches as this might lead to accidents. Such conditions must be avoided in newly built laboratories. The following are some of the principles that should govern the planning of the benching and the services for new laboratories:-

1 Long-term planning is essential. Detailed plans have often to be produced five to 10 years before the laboratory is eventually to be in use.

2 Spare laboratory rooms, without as yet any specific use, should be included in wise planning and these must be adaptable to unexpected uses and laboratory rooms designated for a specific use must also be readily changeable to other purposes. A considerable change in pathological services is to be expected in the next two decades.

3 It must be possible to alter the laboratory to the work that is to be done or to the special requirements of the laboratory worker, and not vice versa.

4 The cost of laboratory benching and services must be kept to a minimum. Much of the benching today is tailor made, often on the site, using expeno sive skilled labour but little mechanization. Costs can be reduced by using factory built, mass-produce unit laboratory furniture. One estimate puts the saving between 10 and 30\% (Skinner, 1961) foì similar quality material.

5 Any future major alterations to the laboratory must be capable of being carried out with the min? mum of disruption of work and with a minimum of expense.

Only a flexible benching system can satisfy ail these requirements. Ideally, the position of services should be interchangeable. The benching, including the sinks, should be mobile and of variable heiglt and the under-bench units should be movable Other laboratory furniture, such as fume cupboards, shelves, and cupboards for apparatus should also be in units and capable of being dismounted. Alteras tions in their arrangement should be capable of being carried out by the laboratory staff without mucko difficulty and without having to call in craftsmer?

Limited flexibility is seen in many modern labord tories. Often under-bench units are movables providing knee spaces and cupboards where requireक but the bench top is fixed in height and one is cone mitted to the position of sinks. Some flexibility of the height of the bench top is available in various com? mercially produced benching systems. In one such system the height of the bench top is variable up ta 3 in. by means of screws. In other systems the heigh? of the bench top is capable of full change fror standing to sitting height by means of mechanicat 


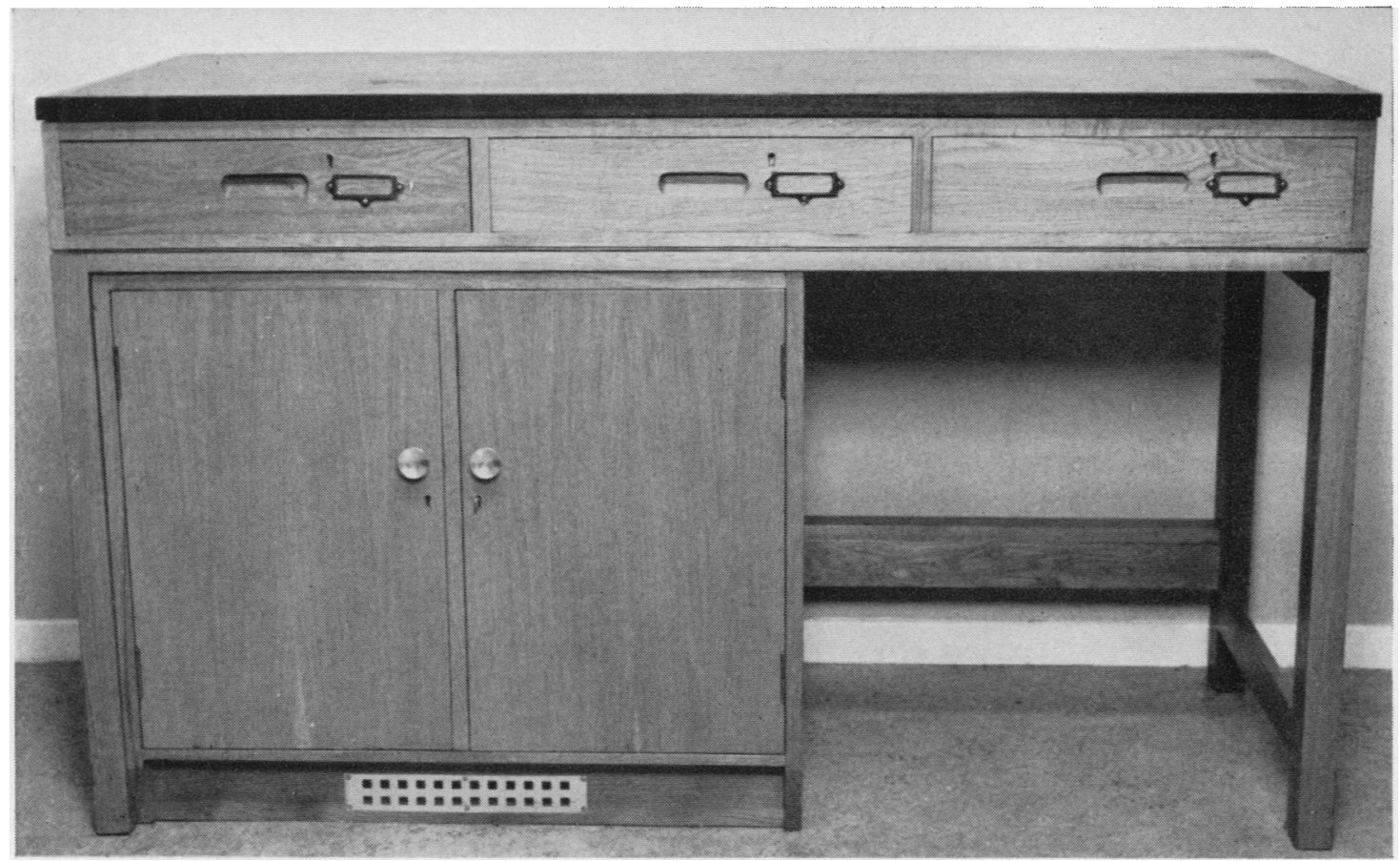

FIG. 1a

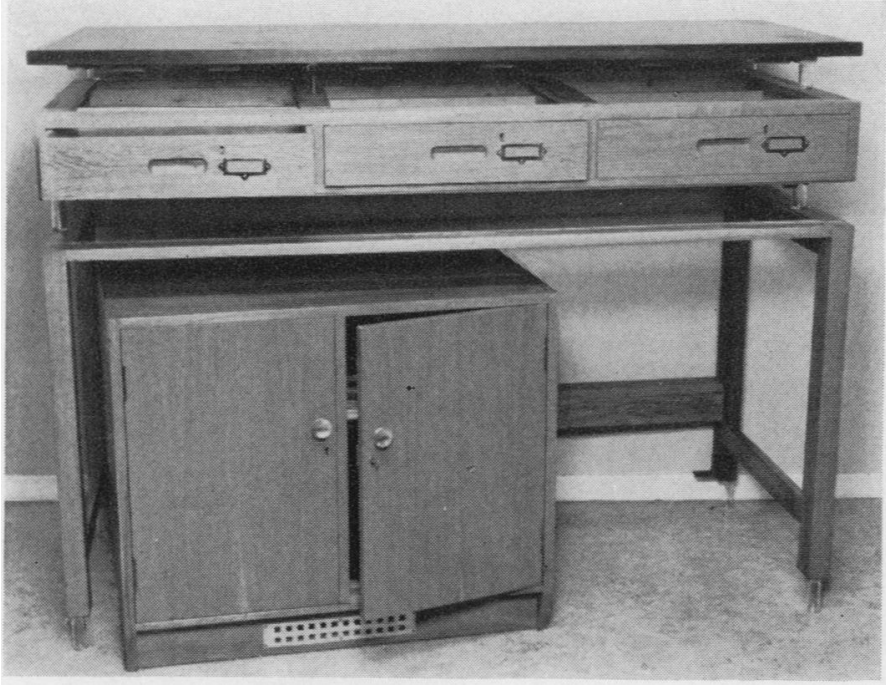

FIG. $1 \mathbf{b}$

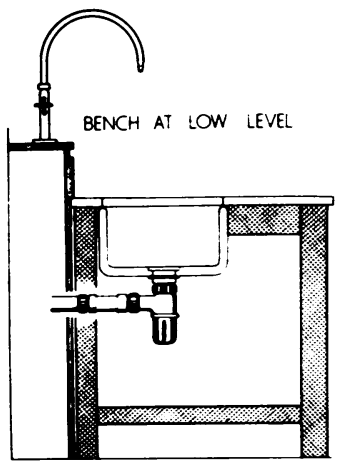

BENCH AT HICH LEVEL

FIG. 2
SSTiS SERICE CASIMC TABLE BASE

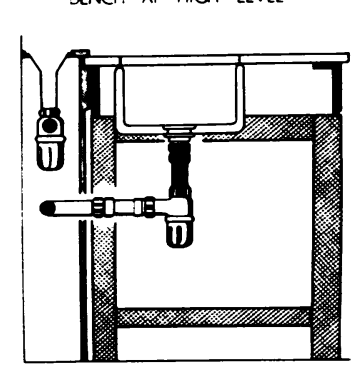

NSERTION PFECES BENCH TOP
FIG. 1a. One $5 \mathrm{ft}$. bench unit employing the Cardiff system at standing height consisting of a bench top $5 \mathrm{ft} . \times 2 \mathrm{ft} .3 \mathrm{in}$., $1 \frac{1}{4} \mathrm{in}$. in thickness, a 6 in. deep insertion unit containing drawers, and a table base. An underbench unit has been added.

FIG. 1b. As above but with the various components spaced to illustrate the system.

FIG. 2. A diagram of the Cardiff benching system showing a bench including a sink at sitting and at standing height to illustrate the principle. The Vulcathene drainage assembly is unscrewed without difficulty.

FIG. 3. The laboratory benching in the Department of Paediatric Pathology of the Welsh National School of Medicine to show a low microscopist's bench with suitable underbench units and knee space and high benches at either side. There is no sink unit to correspond to the water taps so these are deflected into the drip cup and the drainage is closed off with a Vulcathene cap which can just be seen behind the table leg.

FIG. 4. Draughtsman's impression of a peninsular bench for the University Hospital for Wales. All units are mobile or capable of being dismounted and all bench tops of variation in height.

FIG. 5a. The prototype bench designed for the University Hospital for Wales at standing height, employing the Cardiff benching system. The table is of a semi-cantilever steel frame construction, the bench top is of teak on blockboard laminate.

The service casing is shown at the back.

FIG. 5b. A bench unit at sitting height arranged as a desk. The service casing is well shown. 


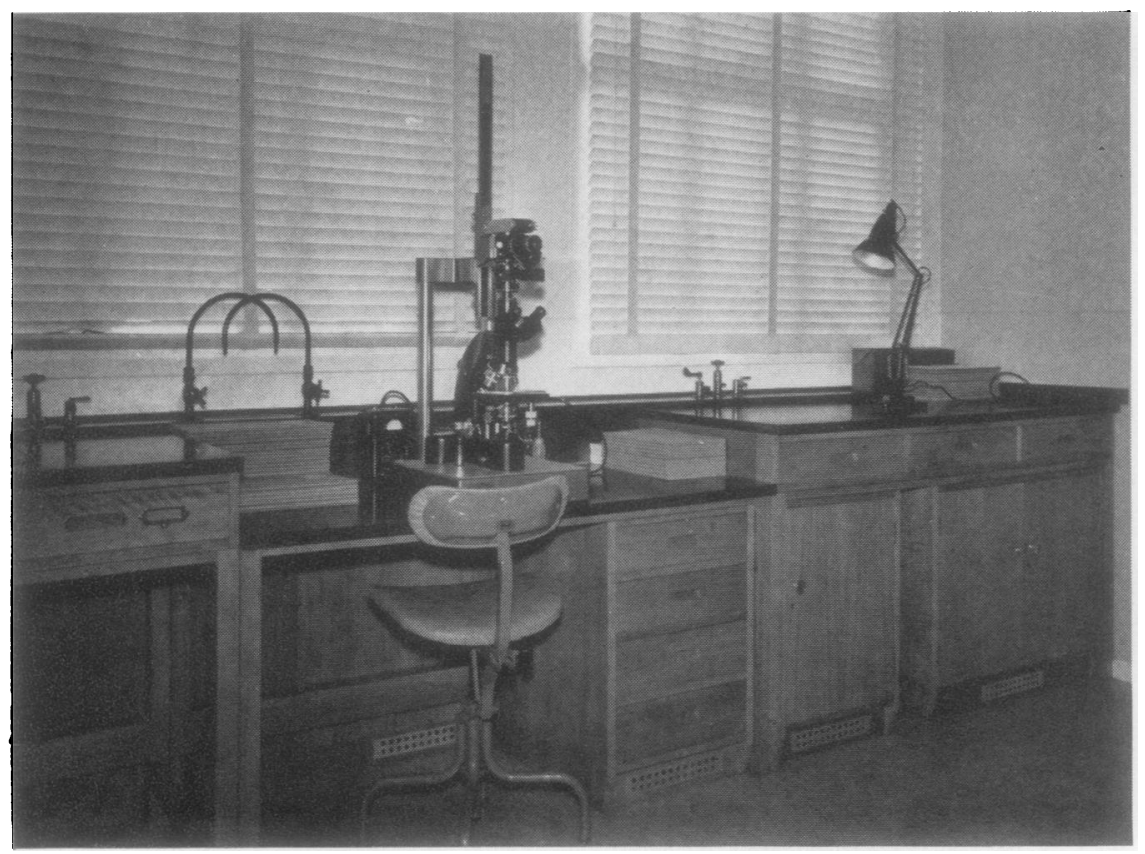

Thanks are due to Mr. Ralph

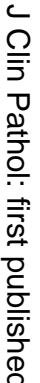

FIG. 3

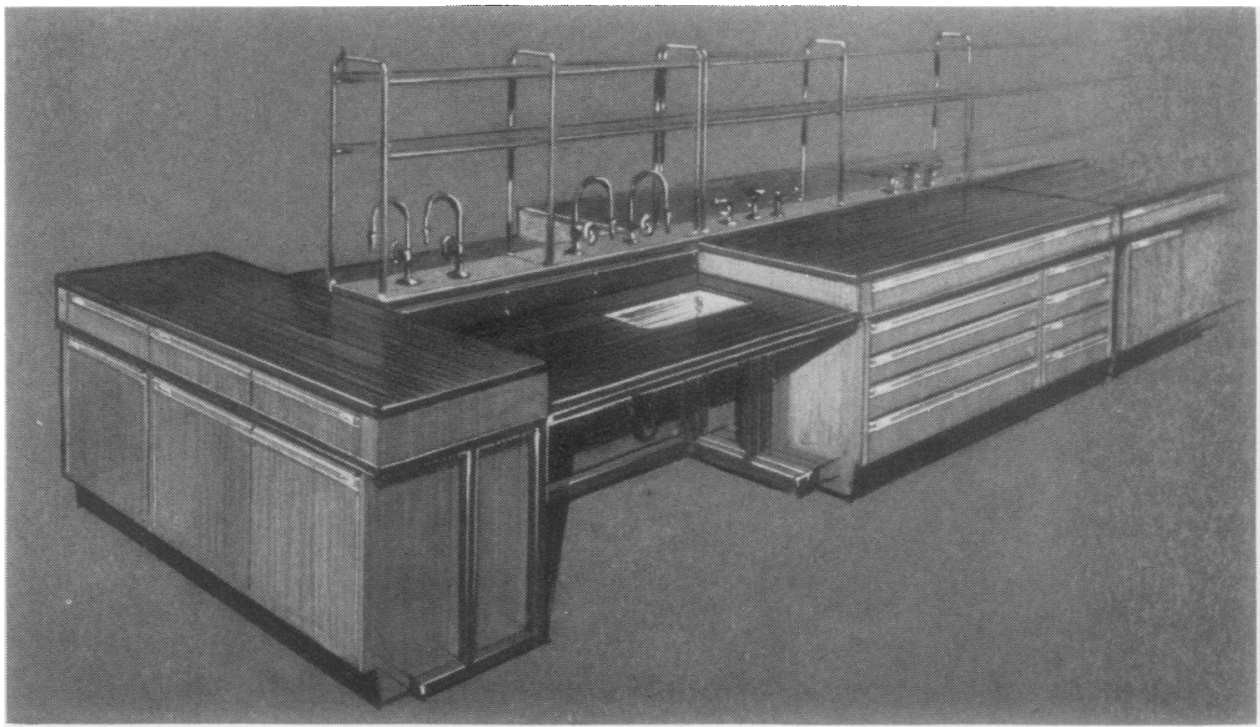

preparing the photographs and charts.

FIG. 4
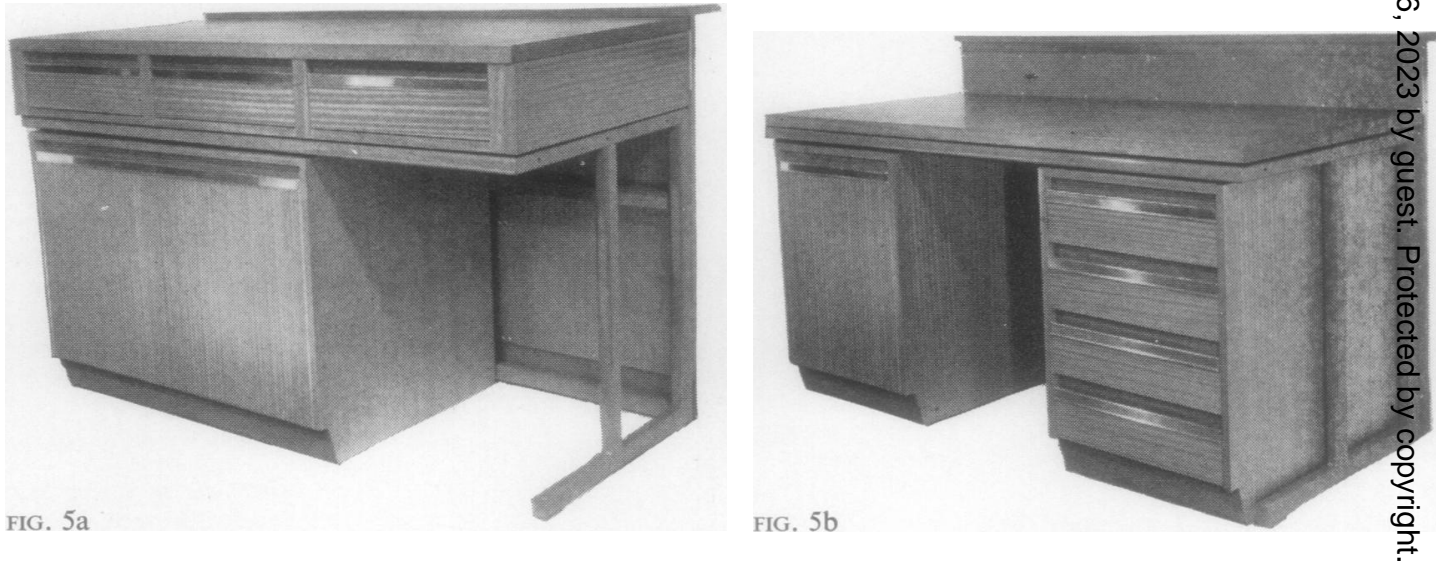
devices. In both these systems there is flexibility of the under-bench units but as the bench units themselves are an intricate part of the service spine they are not readily movable, and those units containing sinks are fixed in position and generally in height.

More flexibility is achieved when all the services are carried on service spines on which the various outlets are repeated at regular intervals and the benches consist merely of tables of unit lengths. Such systems have been designed by Mr. Musgrove of the Nuffield Foundation for the Agriculture Research Council's Animal Research Station, Cambridge (Nuffield Foundation, 1961), and for part of the Imperial Chemical Industries Pharmaceutical Research Station at Alderley Edge, Cheshire. In the latter a $5 \mathrm{ft}$. module was adopted. This system allows flexibility of the benches and under-bench units and has proved quite satisfactory in practice, but it generally does not permit benches with sinks to be mobile and all benches tend to be at a fixed height.

In planning benching for the Department of Paediatric Pathology of the Welsh National School of Medicine, we were trying to combine the flexibility of the benching system used in the biological division of the Imperial Chemical Industries Pharmaceutical Research Station with the variability in bench height of the systems employing mechanical devices. The benching that was designed, and will be called the Cardiff benching system, is composed of units $5 \mathrm{ft}$. long and consists of a table base constructed of wood, a removable bench top of solid Iroko measuring $5 \mathrm{ft} . \times 2 \mathrm{ft} .3$ in. $\times 1 \frac{1}{4}$ in., which is held down by turn buttons. A 6-in. removable insertion piece containing drawers, held in position by guiding plates, enables the height of the bench top to be raised from $2 \mathrm{ft}$. 6 in. to $3 \mathrm{ft}$., that is, from the standard sitting to the standard standing, height (Figs. 1a and $b$ and Fig. 2) ${ }^{1}$. These insertion pieces may be stacked to form a storage unit when not used to make a standing height bench. Movable underbench units, of different types, measuring 28 in. in height just fit under the table base. Some of the bench tops contain sinks provided with sink covers. All services are carried on service spines and the service outlets, which include hot and cold water, together with a drip cup and drainage connexions, are prcvided, for the most part, every $5 \mathrm{ft}$. (Fig. 3). Connexion between the sinks and the drainage points are made with Vulcathene trap units, and the drains themselves are of the same material. Any drainage point not in use is closed off with a Vulcathene cap.

Such a benching system provides great flexibility in height, position of the sinks, and variation in arrangement to suit changing and particular needs.

'Manufactured by the North of England School Furnishing Company Limited, Darlington, County Durham.
It also provides a maximum of unobstructed bench surface as only sinks actually in use interrupt it. The technical staff can easily change the arrangement in a matter of minutes without having to call in maintenance staff. Further, the Vulcathene drains are such that most obstructions are very easily dealt with, again without having to call for the maintenance staff. This system has so far stood the test of time (four years) and all those who have worked with this would be sorry to have to go back to a more fixed type of benching. It is, however, not ideal as the services cannot be dismounted and the material used in the manufacture of the benches is expensive and potentially liable to damage, even though none has occurred to date.

In designing the benching and services for the University Hospital for Wales, the advisory panel on planning laboratories has adopted the Cardiff benching system but has recommended some modifications to the original design (Fig. 4). It has been found that most workers like to work on a teak surface, except for certain specialized purposes when formica or stainless steel is preferable. A teak laminate on block board is more satisfactory than Iroko or solid teak as it is cheaper, does not warp, has most of the resistant qualities of solid teak, and has great resilience, thus reducing breakages. The wooden table base has been replaced by a stove enamelled steel semi-cantilevered base as this has no vulnerable joints and will probably be cheaper when mass produced. Prototypes are being tested (Fig. 5a and Fig. b) and are proving satisfactory and only minor additional modifications may be required.

Probably about $50 \%$ of the under-bench space should be supplied with a variety of different drawer units and cupboards. One sink would be sufficient for every $20 \mathrm{ft}$. of bench, provided that the position of sinks is variable and taps and drip cups are provided every $5 \mathrm{ft}$. on the service boxing. The service boxing, together with its service pipes and outlets, can also be dismounted and is to be built up in $5 \mathrm{ft}$. lengths. Thus, the only permanent fixtures in the new laboratories will be the main window services from which wall or peninsula services may be added from any of a number of points. Cupboards for apparatus, shelves, and fume cupboards are also to be prefabricated and built up in units and are to be capable of being dismounted. When a worker occupies a new room benches, services, and cupboards will be brought from store and fitted to his requirements quickly.

\section{REFERENCES}

Skinner, P. J. (1961). Chem. and Industry, 1099.

Nuffield Foundation Division for Architectural Studies (1961). The Design of Research Laboratories. Oxford University Press, London. 